\title{
MANIFESTAÇÃO E AMBIENTAÇÃO DO INSÓLITO FICCIONAL EM PSICOSE, DE ROBERT BLOCH
}

\section{THE MANIFESTATION AND SETTING OF THE UNCOMMON FICTION IN PSYCHO, BY ROBERT BLOCH}

\author{
Carla Helena Lange ${ }^{1}$ \\ Mauricio Cesar Menon ${ }^{2}$
}

\begin{abstract}
Resumo
Sob a ótica dos estudos literários relacionados ao insólito ficcional, este estudo teve como propósito analisar a construção do espaço e a ambientação do insólito em Psicose (1959), de Robert Bloch. A base teórica deste trabalho está fundamentada nos estudos de literatura fantástica e suas vertentes, principalmente nos conceitos elaborados por Tzvetan Todorov (2003), Remo Ceserani (2006), Howard Phillips Lovecraft (2007) e Edgar Allan Poe (2017). Por fim, foi possível perceber de que forma o insólito, amarrado à ambientação, torna-se fundamental no desenvolvimento do enredo.
\end{abstract}

Palavras-chave: Psicose. Insólito ficcional. Espaço. Ambientação.

\begin{abstract}
From the perspective of literary studies related to uncommon fiction, this study aims to analyze the construction of the space and the unusual setting in Psycho (1959), written by Robert Bloch. The theoretical framework of this work is based on studies about fantastic literature and its aspects, mainly in the concepts pointed out by Tzvetan Todorov (2003), Remo Ceserani (2006), Howard Phillips Lovecraft (2007) and Edgar Allan Poe (2017). Finally, it was possible to see how the uncommon, tied to the setting, become fundamental in the development of the plot.
\end{abstract}

Keywords: Psycho. Uncommon fiction. Space. Setting.

\footnotetext{
${ }^{1}$ Mestranda do Programa de Pós-graduação em Letras (PPGL) da Universidade Tecnológica Federal do Paraná UTFPR, Campus Pato Branco. carllahelena@ hotmail.com

${ }^{2}$ Doutor em Letras pela Universidade Estadual de Londrina (2007). Atualmente é professor da Universidade Tecnológica Federal do Paraná (Departamento de Humanidades DAHUM e do Mestrado em letras PPGL) e Membro de corpo editorial do Diálogo e Interação. mcmenon@utfpr.edu.br
} 
C. H. Lange; M. C. Menon

Manifestação e ambientação do insólito ficcional em Psicose, de Robert Bloch

\section{Considerações iniciais}

Muitos são os estudos literários que se dedicam ao fantástico, sendo possível identificar uma variedade de opiniões e definições acerca do tema. No entanto, foi o búlgaro/francês Tzvetan Todorov um dos primeiros teóricos a organizar, em 1970, um estudo sobre o fantástico, presente no livro Introdução à Literatura Fantástica. Todorov se baseia nos estudos de seus antecessores, especialmente Caillois e Vax, mas inova ao definir a literatura fantástica como um gênero literário e ao trabalhar com a tríade: estranho, maravilho e fantástico (Todorov, 2003).

Contudo, esse esquema triádico apresentado por Todorov foi muito criticado, tendo em vista que foi considerado abstrato, sistemático e perfeito demais. Apesar disso, Remo Ceserani, que também se dedicou ao estudo do fantástico na literatura, concorda com tal ponto da teoria de Todorov, pois, apesar de sistemático, a natureza dialética dessa tríade permite que vários elementos possam promover discussões muito relevantes às análises (CESERANI, 2006).

Não obstante a isso, em determinado momento, Ceserani (2006) também critica a construção teórica da tríade estranho-fantástico-maravilhoso, pois, ao se dedicar à tal estudo, Todorov ignorou as consequências de uma psicologia mais profunda ao utilizar o conceito de "inquietante", formulado por Freud, como "[...] experiência de uma presença perturbadora no cotidiano e de retorno, na idade adulta, de um trauma e de uma angústia infantil deslocada." (CESERANI, 2006, p. 50), a fim de analisar os temas do "eu" e do "tu" que estão ligados à semântica do fantástico.

Dessa maneira, levando em consideração a tríade estranho-fantástico-maravilhoso, Todorov considera o fantástico como um gênero literário, já que este surgiu no século XVIII com o romance gótico e por ser considerado como um gênero, o teórico búlgaro/francês procura sistematizá-lo em categorias, ou seja, apresenta uma visão mais fechada em relação ao fantástico. Já a proposta de Ceserani (2006), apresentada em O Fantástico, pode ser considerada mais ampla, pois enxerga o fantástico como um modo literário que pode operar em variados gêneros e, sendo assim, sempre esteve presente na literatura, uma vez que já existiam cenas fantásticas na literatura antes do século XVIII, basta lembrar de Os Lusíadas, por exemplo.

À vista disso, é possível dizer que a visão de Ceserani não exclui totalmente o que foi proposto por Todorov, mas que se enquadra como uma proposta moderna para o fantástico, 
Manifestação e ambientação do insólito ficcional em Psicose, de Robert Bloch

dado que a teoria de Todorov se detém aos séculos XVIII e XIX. Portanto, é a partir da perspectiva de Ceserani (2006) e dos estudos relacionados ao insólito ficcional que se delineará o presente trabalho, posto que “[...] ele [o fantástico] se considere uma 'contra-forma' ou mais precisamente um 'modo', o fantástico resulta ser uma presença muito forte e persistente na literatura da modernidade." (CESERANI, 2006, p. 65).

Nesse sentido, de acordo com o Dicionário Houaiss da Língua Portuguesa, insólito significa: “adj. 1 Não habitual; estranho; $\neq$ comum. 2 Contrário à tradição e às regras (comportamento i.) $\neq$ tradicional.” (HOUAISS, 2010, p. 441, grifos do autor). Sendo assim, é possível entender que os episódios insólitos são aqueles acontecimentos que não tem o hábito de acontecer, que são incomuns, raros, anormais. Dessa maneira, de acordo com Flavio García, o insólito pode ser visto como os eventos que:

[...] contrariam o uso, os costumes, as regras e as tradições, enfim, surpreendem ou decepcionam o senso comum, às expectativas quotidianas correspondentes a (sic.) dada cultura, a dado momento, a (sic.) dada e específica experienciação da realidade.

É lícito opor o insólito ao natural e ao ordinário, termos comuns na teoria dos gêneros literários quando se quer falar de Maravilhoso, Fantástico, Estranho, Sobrenatural, Realismo Maravilhoso, Absurdo. [...]

Se o insólito não decorre normalmente da ordem regular das coisas, senão que é aquilo que não é característico ou próprio de acontecer, bem como não é peculiar nem presumível nem provável, pode ser equiparado ao sobrenatural e ao extraordinário, ou seja, àquilo que foge do usual ou do previsto, que é fora do comum, não é regular, é raro, excepcional, estranho, esquisito, inacreditável, inabitual, inusual, imprevisto, maravilhoso. (GARCÍA, 2007, p. 19-20).

Nessa lógica, Ceserani, ao utilizar um trecho da novela A casa deserta, de Hoffmann, apresenta uma definição muito profícua para o termo insólito proposta pelo autor de "O homem de areia": “[...] definem-se 'extraordinárias' (ou insólitas) [...] todas as manifestações da consciência e do desejo racionalmente injustificáveis [...]" (HOFFMANN, apud CESERANI, 2006, p. 51). Portanto, é muito provável a presença de eventos insólitos dentro de uma narrativa que trabalhe com o modo fantástico.

Posto isto, este artigo buscará analisar a presença de elementos insólitos na ambientação do romance Psicose, publicado por Robert Bloch em 1959. No que diz respeito à sustentação teórica, utilizar-se-ão alguns conceitos de Tzvetan Todorov (2003), Remo Ceserani (2006), Howard Phillips Lovecraft (2007) e Edgar Allan Poe (2017). 
C. H. Lange; M. C. Menon

Manifestação e ambientação do insólito ficcional em Psicose, de Robert Bloch

A partir de então, o presente trabalho estará dividido em quatro seções, a saber: em " 2 . Ed Gein, Norman Bates e Psicose", será apresentado um breve resumo de Psicose, algumas considerações sobre o autor e, também, será traçada uma relação entre Norman Bates e Ed Gein; “3. A importância da ambientação do espaço insólito”, apresentará e discutirá algumas teorias acerca do espaço e da ambientação narrativa; "4. A dimensão do espaço insólito na casa de Norman Bates", consiste em uma análise da presença do insólito na ambientação do espaço de Psicose; "5. Considerações finais", apresentará os apontamentos finais do trabalho.

\section{Ed Gein, Norman Bates e Psicose}

Publicado originalmente em 1959 pela editora Simon \& Schuster, Psicose é um dos mais de trinta romances do escritor estadunidense Robert Albert Bloch (1917 - 1994) que, além de romances, também foi autor de diversos contos e roteiros para o cinema e televisão. Bloch teve como mentor Howard Phillips Lovecraft, um dos mais importantes escritores de literatura fantástica, o qual incentivava o trabalho de Bloch, que na época era um dos membros mais jovens do chamado Círculo de Lovecraft. Ao longo de sua vida, o escritor de Psicose foi ganhador de diversos prêmios relacionados à Literatura Fantástica, a saber: Hugo Award, Bram Stoker Award, World Fantasy Award, entre outros.

No entanto, ainda em 1959, Psicose ficou fora de circulação durante algum tempo nos Estados Unidos, haja vista que Alfred Hitchcock, diretor da adaptação cinematográfica homônima, comprou os direitos autorais do livro, bem como todos os exemplares das livrarias, porque não queria que ninguém soubesse o final da história antes de assistir ao filme adaptado do romance de Bloch (REBELLO, 2013). Já no Brasil, a obra ficou fora de circulação por quase cinquenta anos, e só ganhou uma nova edição em 2013, produzida pela editora DarkSide ${ }^{3}$. Psicose, de Hitchcock, estreou nos cinemas em 1960 e, sem dúvidas, contribuiu muito para que o romance de Bloch se tornasse mais conhecido.

Para escrever Psicose, Bloch se inspirou na história do serial killer Edward Theodore Gein (1906 - 1984), nascido em La Crosse County - Wisconsin, norte dos Estados Unidos. De acordo com Ilana Casoy (2014), Gein é considerado um dos piores psicopatas de todos os

\footnotetext{
${ }^{3}$ Informações disponíveis em: <http://www.darksidebooks.com.br/psicose/>. Acesso em: 18 jul. 2017.
} 
C. H. Lange; M. C. Menon

Manifestação e ambientação do insólito ficcional em Psicose, de Robert Bloch

tempos, pois além de necrófilo e canibal, ficou muito famoso na década de 1950 por andar em sua propriedade travestido com roupas feitas de pele humana enquanto imitava sua mãe.

Seguindo nesta perspectiva, a narrativa de Psicose se divide em duas tramas: a de Norman Bates, um homem com quarenta anos de idade que vive e administra sozinho seu hotel de beira de estrada, o Bates Motel; e a de Mary Crane, uma secretária com quase trinta anos de idade que sonha em se casar com Sam Loomis, dono de uma loja de ferragens.

Essas duas histórias se cruzam ainda na primeira parte da narrativa, quando Mary rouba quarenta mil dólares da imobiliária onde trabalhava e, após a fuga, hospeda-se no Bates Motel. Como já era noite e chovia muito, Mary jantou com Norman e estranhou o fato de ele e sua mãe morarem sozinhos naquela casa, mas a "Mãe" de Norman Bates era uma pessoa muito dominadora e não ficou feliz ao perceber que o filho estava jantando com outra mulher além de ela mesmo, a Sra. Bates.

Em seguida, enquanto tomava banho, Mary Crane é assassinada pela Sra. Bates, cena que se tornou um ícone do cinema na adaptação de Psicose (1960) feita por Hitchcock. Assim, o desaparecimento de Mary Crane desencadeia uma investigação, além de outras mortes. Por fim, a polícia descobre que, além de se travestir e assumir a personalidade de Norma Bates, Norman havia desenterrado sua mãe que morrera há vinte anos e mantinha o cadáver dentro de sua casa.

Dessa forma, o leitor notará uma ambientação cheia de suspense e horror em Psicose, principalmente na casa e no motel de Norman Bates. Sendo assim, a próxima seção buscará discutir a importância da ambientação do espaço narrativo em Psicose, evidenciando os elementos do insólito que corroboram para gerar o clima de suspense e horror.

\section{A importância da ambientação do espaço insólito}

O espaço é um dos elementos da diegese e, como tal, desenvolve um papel fundamental para a ambientação das cenas dentro da narrativa. Dessa forma, é possível se referir ao espaço por meio de vários sinônimos como "lugar, campo, ambiente, região, setor, universo, paisagem, sítio, extensão, área, faixa, domínio, zona, território etc.” (BRANDÃO, 2013, p. 50).

Nessa perspectiva, é muito comum haver mais de um espaço dentro da narrativa, por isso o espaço analisado neste trabalho será limitado à casa de Norman Bates, local em que ele dizia morar com sua mãe. A estrutura da casa está disposta na narrativa pelos seguintes espaços: 
C. H. Lange; M. C. Menon

Manifestação e ambientação do insólito ficcional em Psicose, de Robert Bloch

porão, local pouco iluminado onde Norman praticava a taxidermia; térreo, composto pela sala de estar, sala de jantar e cozinha; primeiro andar, onde estavam localizados o banheiro, o quarto de Norman e o quarto de Norma Bates. Nesse sentido, Oliveira e Gama-Khalil afirmam que:

É comum no decorrer das narrativas fantásticas que o espaço mude, sofra alterações, propiciando um imbricamento entre duas ou mais dimensões dentro de uma aparentemente única espacialidade, visto que se migra de um espaço semelhante ao mundo real, regido pelas mesmas leis naturais e familiares para um mundo novo, controlado por novas e diferentes leis naturais, povoado por seres poli e multiformes. (OLIVEIRA; GAMAKHALIL, 2016, p. 8, grifos nossos).

Com efeito, conforme poderá ser visto mais detalhadamente na próxima seção, há mais de uma dimensão dentro de um único espaço na narrativa de Psicose. Além do mais, nesse caso, como em muitas outras narrativas fantásticas, o espaço tem grande influência na construção da ambientação do insólito, basta lembrar, por exemplo, o conto "A queda da casa de Usher", de Edgar Allan Poe, em que o espaço da casa é fundamental para ambientar o tom de mistério na trama, além de também configurar a casa como uma personagem da história. Sendo assim, a importância do espaço e de "[...] seus gêneros adjacentes têm em âmago a peculiaridade de [...] conectar, confrontar ou colocar em intersecção mundos distintos, espaços divergentes, realidades incongruentes." (VOLOBUEF, 2012, p.175, apud OLIVEIRA; GAMA-KHALIL, 2016, p. 3).

Em Psicose, quando Lila, irmã de Mary, decide vasculhar a casa de Norman e, ao descrever pela primeira vez a aparência da casa, tem a sensação de estar em um lugar que não condiz com a realidade, pois a casa parecia ter vida própria:

Lila subiu os degraus e chagou à varanda bem na hora em que a chuva desabou.

A casa era velha e sua estrutura de madeira era gasta e cinzenta à meia-luz da tormenta que se aproximava. $\mathrm{O}$ assoalho da varanda rangia sob seus pés e ela podia ouvir o vento chacoalhando os caixilhos das janelas do primeiro andar. [...]

Lila bateu de novo, e a casa gemeu um eco cavernoso, o som da chuva abafou. Ela não se deu ao trabalho de tentar ouvir melhor. (BLOCH, 2013, p. 209, grifos nossos).

Já nessa primeira descrição da aparência externa da casa de Norman Bates, nota-se a forma com que a ambientação conduz para um espaço sombrio e misterioso que, mais adiante, vai aterrorizar a personagem Lila. Portanto, é possível perceber a importância da ambientação 
C. H. Lange; M. C. Menon

Manifestação e ambientação do insólito ficcional em Psicose, de Robert Bloch

do espaço insólito para uma história fantástica, mesmo essa não envolvendo elementos sobrenaturais.

Conforme foi dito na seção anterior, Robert Bloch pertencia ao círculo de H. P. Lovecraft e, sendo assim, é inegável que sua literatura teve influência de seu mentor, que também era teórico acerca da literatura fantástica. Em um de seus livros sobre o tema, $O$ horror sobrenatural em literatura, publicado originalmente em 1927, Lovecraft traz o seguinte pensamento sobre a natureza humana:

A emoção mais forte e mais antiga da humanidade é o medo, e o tipo de medo mais antigo e mais poderoso é o medo do desconhecido. Poucos psicólogos contestarão esses fatos e sua reconhecida verdade deve estabelecer, para todos os tempos, a autenticidade e dignidade da ficção fantástica de horror como forma literária. (LOVECRAFT, 2007, p. 13, grifos nossos).

Como recordamos a dor e a ameaça da morte mais vivamente que o prazer, e como nossos sentimentos para com os aspectos benfazejos do desconhecido foram, desde o início, captados e formalizados por rituais religiosos convencionais, coube ao lado mais escuro e maléfico do mistério cósmico reinar em nosso folclore sobrenatural popular. [...] Quando se sobrepõe a esse senso de medo e de mal o inevitável fascínio do maravilhoso e da curiosidade, nasce um conjunto composto de emoção aguda e provocação imaginativa cuja vitalidade deve necessariamente durar enquanto existir a raça humana. (LOVECRAFT, 2007, p. 15-16, grifos nossos).

Nesse sentido, pode-se dizer que o fascínio e a curiosidade de Mary Crane pela história de Norman Bates que contribuem para que ela seja morta. Sem saber que estava conversando com um psicopata e que este não gostava quando lhe perguntavam sobre sua mãe, Mary acaba gerando uma insatisfação em Norman:

[...] Comparada com ele, Mary sentia-se com dois metros de altura. [...]

'Senhor Bates, me desculpe por dizer isto, mas por quanto tempo pretende continuar assim? O senhor é um homem adulto. Com certeza compreende que não pode se comportar como uma criança pelo resto da vida. Não quero ser grosseira, mas...'

'Eu compreendo. [...] Mas tenho um dever a cumprir em relação à minha mãe.' 'E não estaria cumprindo esse dever, em relação a ela e a si mesmo, se a mandasse... para uma instituição?'

'Ela não está louca!'

A voz já não era macia nem em tom de desculpas: era alta e estridente. $\mathrm{O}$ homem rechonchudo estava de pé, suas mãos varrendo uma xícara da mesa. Ela se espatifou no chão, mas Mary só tinha olhos para aquele rosto transfigurado.

'Ela não está louca', ele repetiu. [...] (BLOCH, 2012, p. 49-50, grifos do autor). 
C. H. Lange; M. C. Menon

Manifestação e ambientação do insólito ficcional em Psicose, de Robert Bloch

De certa maneira, essa reação de Norman faz com que Mary sinta medo, um medo do desconhecido, um medo do que Freud (1977) chama de "estranho familiar", talvez um pressentimento do que está por vir, tanto que, ao chegar em seu quarto, a moça se questiona: "De repente, já não se sentia com dois metros de altura. Mas a mudança fora assim tão rápida? Ou começara quando o senhor Bates tinha ficado histérico, lá na casa? O que ele tinha dito realmente a desanimara?" (BLOCH, 2013, p. 52, grifos nossos). Além do pânico que Mary começara a sentir, outro fator importante na citação acima é o fato de que Norman se exaltou pela primeira vez com Mary dentro de sua casa o que, mais uma vez, demonstra a influência do ambiente da casa sob Norman. Em relação a isso, Lovecraft afirma que a atmosfera é o elemento mais importante para determinar sensações:

Evidentemente não podemos esperar que todas as histórias fantásticas se conformem à perfeição com algum modelo teórico. As mentes criativas são desiguais, e o melhor dos tecidos tem seus pontos frouxos. Ademais, boa parte da obra fantástica seleta é inconsciente, aparecendo em fragmentos memoráveis espalhados por material cujo efeito geral pode ser de molde muito diferente. Atmosfera é a coisa mais importante, pois o critério final de autenticidade não é a harmonização de um enredo, mas a criação de uma determinada sensação. (LOVECRAFT, 2007, p. 17, grifos nossos).

Sob o mesmo ponto de vista, o mestre das narrativas de terror e mistério que influenciou muito H. P. Lovecraft, Edgar Allan Poe, ao fazer um estudo teórico acerca de "O Corvo", em 1846 (vide “A filosofia da composição"), defende que quanto mais fechado é o espaço, mais forte será a ambientação do horror:

O próximo ponto a ser considerado foi o modo de reunir o enamorado com o corvo - e a primeira escolha a ser feita dizia respeito ao lugar onde se encontrariam. A sugestão mais natural seria em uma floresta ou em um campo, mas sempre me pareceu que a restrição de um espaço fechado era absolutamente necessária para criar o efeito de um incidente isolado, como uma moldura em um quadro. Possui o incontestável dom moral de manter a atenção concentrada e, é claro, não deve ser confundida com uma mera unidade local. (POE, 2017, p. 349-350, grifos do autor).

À vista disso, nota-se a preocupação de Robert Bloch em desenvolver as cenas de horror nos ambientes mais fechados da casa e do motel como, por exemplo, o assassinato do detetive Arbogast, que acontece no vestíbulo da casa de Norman, e o encontro de Mary com Norma, que se passa no banheiro de um quarto do motel, conforme pode ser observado a seguir: 
C. H. Lange; M. C. Menon

Manifestação e ambientação do insólito ficcional em Psicose, de Robert Bloch

Não podia ouvir nada além do barulho da água, e o banheiro começou a se encher de vapor.

Foi por isso que não percebeu a porta abrir, nem o som de passos. Logo que as cortinas do chuveiro se abriram, o vapor obscureceu o rosto.

Então ela viu - um rosto, espiando entre as cortinas, flutuando como uma máscara. Um lenço escondia os cabelos e os olhos vidrados a observavam, inumanos. Mas não era uma máscara, não podia ser. Uma camada de pó dava à pele uma brancura de cadáver; havia duas manchas de ruge nas maçãs do rosto. Não era uma máscara. Era o rosto de uma velha louca.

Mary começou a gritar. A cortina se abriu mais e uma mão apareceu, empunhando uma faca de açougueiro. E foi a faca que, no momento seguinte, cortou o seu rito.

E a sua cabeça. (BLOCH, 2013, p. 55, grifo do autor).

É imaginável a sensação aterrorizadora vivida por Mary naquele instante, tanto que é muito provável que essa sensação também seja sentida pelo leitor, tendo em conta que ao descrever esse espaço pequeno, fechado, cheio de vapor e com a água abafando o barulho externo, o narrador faz com que o susto de Mary ao encontrar Norman travestido com as roupas de sua mãe e com uma faca na mão, seja ainda maior.

Por fim, Lovecraft ressalta que são os toques atmosféricos, isto é, a ambientação da história, a composição dos cenários, juntamente com a habilidade do escritor em trabalhar com esses elementos, que produzem a sensação de horror e sobrenatural:

Podemos dizer, generalizando, que uma história fantástica cuja intenção seja ensinar ou produzir um efeito social, ou uma em que os horrores são explicados no final por meios naturais, não é uma genuína história de medo cósmico; mas persiste o fato de que essas narrativas muitas vezes possuem, em seções isoladas, toques atmosféricos que preenchem todas as condições da verdadeira literatura de horror sobrenatural. Portanto, devemos julgar uma história fantástica, não pela intenção do autor ou pela simples mecânica do enredo, mas pelo nível emocional que ela atinge em seu ponto menos banal. Se as sensações apropriadas forem provocadas, esse 'ponto alto' deve ser admitido, por seus próprios méritos, como literatura fantástica, pouco importando quão prosaicamente ele seja degradado na sequência. O único teste do realmente fantástico é apenas este: se ele provoca ou não no leitor um profundo senso de pavor e o contato com potências e esferas desconhecidas; [...]. (LOVECRAFT, 2007, p. 17-18).

A fim de entender como o insólito, dentro daquele cenário, é construído na narrativa de Robert Bloch, a próxima seção terá como foco o estudo da ambientação dos espaços da casa de Norman. 


\section{A dimensão do espaço insólito na casa de Norman Bates}

Em The pervert's guide to cinema (2006), Slavoj Žižek, filósofo, psicanalista e crítico teórico esloveno, faz uma análise sobre o filme Psicose (1960), dirigido por Hitchcock, que serve como base de estudo para a narrativa de Robert Bloch, dado que o cineasta não fez muitas alterações na história de Norman Bates. De acordo com Žižek (2006), a disposição dos ambientes da casa dos Bates reflete muito no comportamento de Norman, uma vez que os três espaços da casa (primeiro andar, térreo e porão) reproduzem os três níveis da subjetividade humana.

Sendo assim, com base nos estudos de Sigmund Freud (2011) acerca do Eu e do Id, o andar térreo representaria o Ego de Norman, uma vez que neste andar ele se comporta como um filho normal, ou com o pouco que resta do seu Ego no comando (ŽIŽEK, 2006, 00:08:45). Já o segundo andar, lugar onde se encontram os quartos de Norman e Norma, seria o Superego, já que quando está nesse espaço Norman age com seu Superego materno, visto que a mãe morta é a principal figura de seu Superego (ŽIŽEK, 2006, 00:09:30). Por fim, o porão é comparado ao Id, pois é o local que serve como um reservatório dessas pulsões ilícitas, no qual Norman deixa guardado, sempre que necessário, o cadáver de sua mãe (ŽIŽEK, 2006, 00:10:02).

A partir dessa formulação apresentada por Žižek, percebe-se como a disposição do espaço representa as personalidades de Norman. Portanto, a seguir serão analisadas algumas cenas da narrativa de Bloch que demonstram como o espaço, além de interferir na personalidade de Norman, também gera uma ambientação insólita.

Nesse sentido, as cenas que melhor descrevem a casa dos Bates estão sob o ponto de vista de Lila, que após o desaparecimento de Mary decide procurá-la chegando, assim, até Norman Bates. Logo na entrada da casa, a aparência e decoração antigas perturbam muito Lila que, em decorrência disso, sente um clima muito estranho no ambiente:

Lila entrou no vestíbulo. Estava mais escuro do que a varanda. Mas deveria haver um interruptor em algum lugar ao longo da parede.

Ela o encontrou e acendeu a luz. A lâmpada do teto, sem luminária, dava uma claridade débil, doentia, contra o fundo de papel de parede descascado. O que eram aqueles desenhos - cachos de uvas, violetas? Pavorosos. Coisas do século passado.

Um olhar de relance na sala confirmou a impressão. Lila não quis entrar. As salas do andar térreo poderiam ficar para mais tarde. Arbogast tinha dito que 
C. H. Lange; M. C. Menon

Manifestação e ambientação do insólito ficcional em Psicose, de Robert Bloch

vira alguém espiando de uma janela no andar de cima. Era por lá que deveria começar.

Na escada não havia interruptor. Subiu devagar, tateando o corrimão, ao chegar ao patamar, o trovão estrondou. A casa inteira pareceu chacoalhar. Lila sentiu um tremor involuntário, depois relaxou. Foi sem querer, disse a si mesma. Perfeitamente natural. Certamente, não havia nada capaz de assustar alguém naquela casa vazia. (BLOCH, 2013, p. 211).

Destarte, é perceptível a preocupação do narrador em descrever o espaço e a ambientação muito minuciosamente, tanto que o suspense vai aumentando na medida em que se vai lendo o texto. A escolha da ambientação noturna, com trovões e muita escuridão, também corroboram muito para a construção desse espaço de horror, pois, conforme aponta Ceserani, “A ambientação preferida pelo fantástico é aquela que remete ao mundo noturno." (2006, p. 77).

Seguindo na descrição da casa, Lila chega ao quarto de Norman e se espanta com o que encontra lá:

Escolheu a segunda porta e acendeu a luz. Outra lâmpada fraca e nua no teto, mas a luz era suficiente para que pudesse ver o quarto. $\mathrm{O}$ dormitório de Bates - estranhamente exíguo, estranhamente apertado, com um estrado mais apropriado para um menino do que para um homem. [...] A cama estava em desordem, com sinais de ter sido ocupada recentemente. [...]

A segunda gaveta era de camisas; a terceira de meias e roupa íntima. A última continha roupas brancas amarfanhadas, que ela finalmente - sem poder acreditar - identificou camisolas. [...] (BLOCH, 2013, 212-213).

É somente a partir daí, ou seja, a partir do momento que Lila chega ao primeiro andar da casa, que ela se dá conta do real perigo que está correndo, pois é como se ela estivesse acesso ao superego de Norman que é, na verdade, o espaço de Norma, sua mãe. No entanto, a situação se agrava um pouco mais quando ela chega ao quarto de Norma:

Franzindo o cenho, retornou ao vestíbulo. A chuva caía forte no telhado e o trovão roncava quando abriu a terceira porta almofadada. Por um momento ficou imóvel olhando o escuro, inalando o cheiro enjoativo, misto de mofo, perfume rançoso... e o que mais? [...]

A decoração daquele quarto já era antiquada muitos anos antes da morte da mãe de Bates. [...] um quarto com cadeiras de balanço, gatos de porcelana, colchas bordadas a mão e cadeiras excessivamente estofadas e encapadas.

E ainda estava vivo. (BLOCH, 2013, p. 214, grifos do autor).

De fato, o quarto de Norma transmite uma sensação mais perturbadora ainda, com a ajuda de elementos externos, a chuva forte e as trovoadas, somados à escuridão interna e ao 
C. H. Lange; M. C. Menon

Manifestação e ambientação do insólito ficcional em Psicose, de Robert Bloch

cheiro de podridão, a presença do insólito se faz de tal forma que o quarto parece estar vivo. Adiante, o narrador continua a descrever o espaço dos quartos:

Era isso que fazia com que se sentisse viajando no tempo e no espaço. No andar térreo, havia restos de um passado que a decadência devastara; no segundo andar, tudo era abandono e feiura. Mas aquele quarto era controlado, consistente, coerente - uma entidade vital e funcional, completa em si mesma. Absolutamente limpo, imaculadamente isento de poeira e perfeitamente organizado. Quando se ignorava o cheiro de bolor, não se tinha a impressão de estar em um museu ou em uma exposição. O quarto estava vivo, como em qualquer quarto em que se viveu por muito tempo. Mobiliado havia cinquenta anos, vago e intocado desde a morte de sua ocupante há vinte anos, ainda se diria que era o quarto de uma pessoa viva. Um quarto no qual, na véspera, uma mulher se sentara junto da janela e olhara para fora...

Não há fantasmas, Lila disse a si mesma. Franziu a testa ao perceber que tinha sido necessário negar para si. E, no entanto, ela podia sentir uma presença viva ali. (BLOCH, 2013, p. 215, grifos do autor).

Dessa forma, percebe-se mais de uma dimensão no mesmo espaço: (1) a dimensão de vinte anos atrás, quando Norma ainda estava viva, considerando que suas coisas permanecem intactas e isso sugere a presença dela no ambiente; (2) a dimensão da loucura de Norman que acontece quando ele assume a personalidade da falecida mãe; (3) a dimensão de Norman adulto, homem que se interessa muito pela leitura, especialmente de livros ligados à psicologia; (4) a dimensão da realidade, o universo de Lila, Mary, Arbogast e Sam. De acordo com Ceserani, é muito comum haver mais de uma dimensão dentro do mesmo espaço na narrativa fantástica: "Várias vezes encontramos, nos contos fantásticos que lemos, exemplos de passagem da dimensão do cotidiano, do familiar e do costumeiro para a do inexplicável e do perturbador: passagem de limite [...] da dimensão da realidade para a [...] da loucura." (CESERANI, 2006, p. 73).

Não obstante, o ponto culminante do horror na narrativa não é o momento em que Mary foi morta com várias facadas, mas sim quando Lila encontra o porão da casa de Norman, isto é, quando ela tem acesso ao seu Id e descobre os piores comportamentos do protagonista de Psicose:

A escada do porão estava bem à frente. Tateou a parede até que sua mão encontrou outro interruptor. A luz se acendeu lá embaixo, apenas um clarão fraco e vacilante nas profundezas do escuro. O trovão roncava, em contraponto às batidas dos seus saltos.

A lâmpada se balançava por um fio bem em frente à caldeira. Era uma caldeira grande, com uma porta de ferro, pesada. Lila parou ali, olhando para ela. Estrava tremendo, admitia agora para si mesma; [...] 
C. H. Lange; M. C. Menon

Manifestação e ambientação do insólito ficcional em Psicose, de Robert Bloch

A manta tapava completamente, mas deveria haver um quarto por trás dela, [...] um lugar ideal para alguém se esconder e esperar.

Lila abriu a porta do depósito de frutas.

Foi aí que gritou.

Gritou ao ver a velha deitada ali, uma velha emaciada, de cabelos brancos, com o rosto enrugado e escuro, arregrava os dentes para ela, num sorriso obsceno.

'Senhora Bates!', gritou Lila.

'Sim'.

Mas a voz não estava saindo das mandíbulas fundas, endurecidas. Veio de algum lugar por trás dela [...]. (BLOCH, 2013, p. 217-219, grifo do autor).

Nessa perspectiva, é notável a forma com que o narrador conduz a descrição do espaço e a ambientação narrativa de um clima de horror, sugerindo, muitas vezes, a presença do insólito, conforme foi apontado acima. Sendo assim:

As explicações freudianas dos atos do psicopata Norman Bates não o tornam menos perigoso, e nem fazem o leitor e os protagonistas o temerem menos. Portanto, dar uma explicação racional aos atos do "monstro" de uma história de horror pode funcionar como uma forma de intensificar o efeito de horror, pois revelam dados que geram mais desconforto. (DUTRA, 2015, p. 79).

Dessa forma, é possível afirmar que há a presença do "estranho familiar" em Norman Bates, o qual é definido por Freud como "[...] nada novo ou alheio, porém algo que é familiar e há muito estabelecido na mente, e que somente se alienou desta através do processo da repressão.” (FREUD, 1977, p. 258). Isto quer dizer que, por mais que não tenha a presença de algo sobrenatural em Psicose, a presença do horror e do medo é tão intensa quanto em uma história de fantasmas, por exemplo. Com efeito, vale ressaltar que, além do espaço e ambientação, o narrador também contribui na construção desse clima insólito, tendo em conta que a descrição da personagem Norma não causa um medo imediato em Mary, mas sim um estranhamento de algo familiar. Isso se deve especialmente pela imagem duplicada de Norman e Norma e pelo Complexo de Édipo existente nessa relação entre mãe e filho.

Assim sendo, a explicação do insólito por meio da psicanálise em Psicose causa mais medo nas personagens da narrativa, tendo em vista que é algo muito próximo do ser humano, algo que é comprovado cientificamente e que pode ocorrer com qualquer pessoa, mas, ao mesmo tempo, ninguém espera ou acredita que isso pode acontecer. 
C. H. Lange; M. C. Menon

Manifestação e ambientação do insólito ficcional em Psicose, de Robert Bloch

\section{Considerações finais}

Mediante ao exposto, pode-se dizer que o fantástico ocorre de várias formas na literatura e que, mesmo sendo considerado como um gênero literário (Todorov) ou um modo (Ceserani), a presença do insólito, isto é, do incomum, do estranho, do raro, é algo que caracteriza uma narrativa como fantástica.

Dessa forma, verificou-se que em Psicose, de Robert Bloch, há a presença do "estranho familiar" de Freud (1977) em Norman Bates. Além disso, também foi possível discutir a forma com que o insólito foi construído na narrativa de Bloch e como este modificou a ambientação da história.

Outrossim, mediante a abordagem teórica em relação ao espaço e a ambientação narrativa, apresentada principalmente por H. P. Lovecraft, chegou-se à conclusão de que é a partir dos elementos insólitos utilizados para descrever o espaço que a ambientação ganha um clima fantástico.

Por fim, pode-se dizer que Psicose, de Robert Bloch, se encaixa nas narrativas fantásticas, considerando que o autor soube utilizar muito bem os elementos insólitos para criar um espaço com uma ambientação cheia de suspense, mistério, horror e medo. Além disso, também merece destaque a forma com que Norman Bates age em cada espaço de sua casa, fazendo com que cada cômodo remeta a um nível de sua doença.

\section{Referências}

BLOCH, Robert. Psicose. Tradução Anabela Paiva. Rio de Janeiro: DarkSide Books, 2013. BRANDÃO, Luis Alberto. Teorias do espaço literário. São Paulo: Perspectiva; Belo Horizonte, MG: FAPEMIG, 2013.

CESERANI, Remo. O Fantástico. Tradução de Nilton Cezar Tridapalli. Curitiba: Ed. UFPR, 2006.

COSOY, Ilana. Serial killers: louco ou cruel? Rio de Janeiro: DarkSide Books, 2014.

DARKSIDE. Psicose: classic edition. Disponível em: <http://www.darksidebooks.com.br/psicose/>. Acesso em: 18 jul. 2017.

DUTRA, Daniel Iturvides. O horror sobrenatural de H.P. Lovecraft: teoria e praxe estética do horror cósmico. 2015. 263 f. Tese (Doutorado em Literatura Comparada) - Programa de 
C. H. Lange; M. C. Menon

Manifestação e ambientação do insólito ficcional em Psicose, de Robert Bloch

Pós-Graduação em Letras, Universidade Federal do Rio Grande do Sul, Porto Alegre, 2015. Disponível em: <http://www.lume.ufrgs.br/handle/10183/128999>. Acesso em: 14 jul. 2017.

FREUD, Sigmund. O estranho (1919). In: Uma neurose infantil e outros trabalhos,

Vol. XVII. Rio de Janeiro: Imago, 1977, p. 273-314. Disponível em: $<$ http://conexoesclinicas.com.br/wp-content/uploads/2015/01/freud-sigmund-obrascompletas-imago-vol-17-1917-1918.pdf>. Acesso em: $01 \mathrm{dez} .2017$.

O Eu e o Id (1923). In: Obras completas, volume 16: O Eu e o Id, “autobiografia" e outros textos (1923-1925). Tradução: Paulo César de Souza. São Paulo: Companhia das Letras, 2011. Disponível em: <https://www.companhiadasletras.com.br/trechos/13032.pdf>. Acesso em: 01 dez. 2017.

GARCÍA, Flavio (org.). A banalização do insólito: questões de gênero literário - mecanismos de construção narrativa. Rio de Janeiro: Dialogarts, 2007. Disponível em: $<$ http://www.dialogarts.uerj.br/admin/arquivos_tfc_literatura/livro_insolito.pdf >. Acesso em: 14 jul. 2017.

HOUAISS, Antônio; VILLAR, Mauro de Salles. Minidicionário da língua portuguesa. 4. ed. Rio de Janeiro: Objetiva, 2010.

LOVECRAFT, Howard Phillips. O horror sobrenatural em literatura. Tradução Celso M. Paciornik. São Paulo: Iluminuras, 2007.

OLIVEIRA, Bruno Silva de; GAMA-KHALIL, Marisa Martins. O espaço como elemento irradiador do medo na literatura sertanista de Afonso Arinos e Bernardo Guimarães. Abusões, v. $1, \quad$ n. $\quad 1, \quad 2016 . \quad$ Disponível em: <http://www.epublicacoes.uerj.br/index.php/abusoes/article/view/22022/18384>. Acesso em: 14 jul. 2017. POE, Edgar Allan. A filosofia da composição. In: Medo clássico: Edgar Allan Poe: coletânea inédita de contos do autor. Tradução Marcia Heloisa Amarante Gonçalves. Rio de Janeiro: DarkSide Books, 2017.

REBELLO, Stephen. Alfred Hitchcock e os bastidores de Psicose. Tradução Rogério Durst. Rio de Janeiro: Intrínseca, 2013.

THE pervert's guide to cinema. Direção: Sophie Fiennes. Produção: Amoeba Film. Roteiro: Slavoj Žižek. Reino Unido, Áustria, Holanda: Amoeba Film, 2006, 153 min., color., 35 mm., DVD. 
C. H. Lange; M. C. Menon

Manifestação e ambientação do insólito ficcional em Psicose, de Robert Bloch

TODOROV, Tzvetan. Introdução à Literatura Fantástica. $2^{\mathrm{a}}$ Ed. São Paulo: Perspectiva, 2003.

Artigo recebido em: 02/08/2018

Artigo aceito para publicação em: 08/09/2018 